\title{
Prevalence of depression and associated factors among elderly Sudanese: a household survey in Khartoum State
}

\author{
S.M. Assil' ${ }^{1}$ and Z.A. Zeidan ${ }^{2,3}$
}

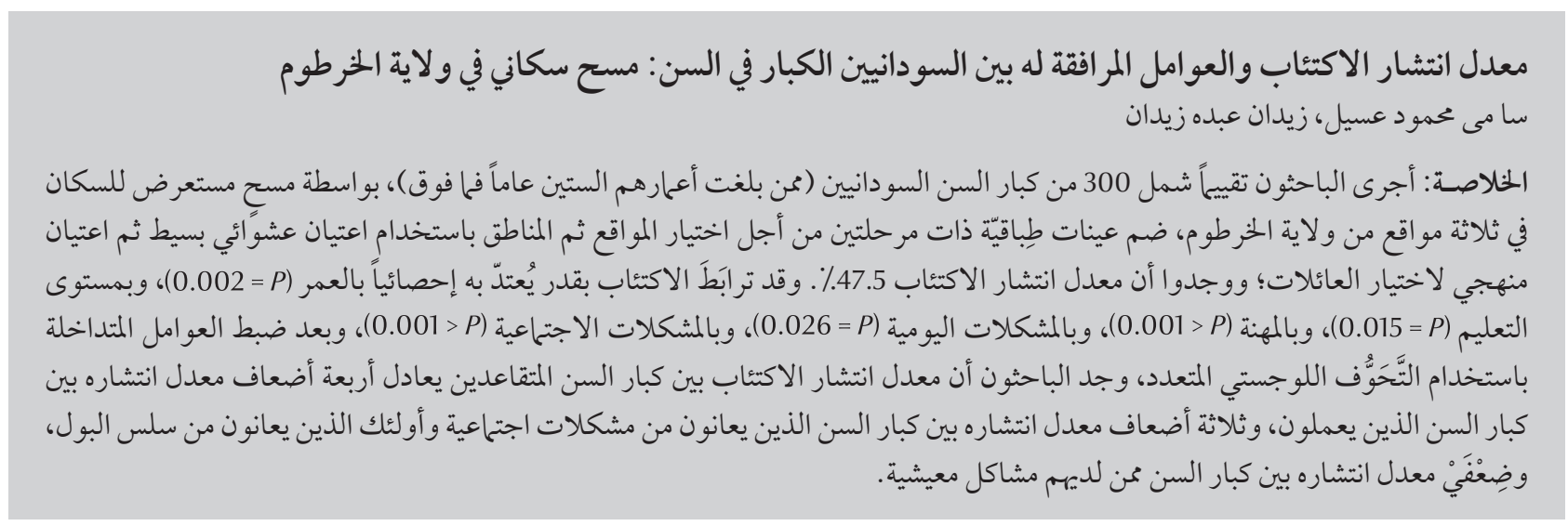

ABSTRACT We assessed depression among 300 elderly Sudanese (age 60+ years). We conducted a cross-sectional household survey in 3 localities in Khartoum State. A 2-stage stratified sampling was carried out to select the localities and then the areas using simple random sampling; then systematic random sampling was used to select households. The prevalence of depression was 47.5\%. Depression was significantly associated with age $(P=0.002)$, level of education $(P=0.015)$, occupation $(P<0.001)$, the problems of everyday living $(P=0.026)$, and social problems $(P<0.001)$. After controlling for confounders using multiple logistic regression, we found that depression was 4 times greater among the elderly retired compared to the elderly working, 3 times greater among the elderly with social problems and those who were suffering from urine incontinence and 2 times greater among the elderly with living problems.

Prévalence de la dépression et des facteurs associés chez des Soudanais âgés : enquête auprès des ménages dans l'État de Khartoum

RÉSUMÉ Nous avons évalué la dépression chez 300 Soudanais âgés de plus de 60 ans. Nous avons mené une enquête transversale auprès des ménages dans trois localités de l'État de Khartoum. Un échantillonnage stratifié à deux degrés a été réalisé pour sélectionner les localités, puis les zones ont été choisies à l'aide d'un échantillonnage aléatoire simple et les ménages par un échantillonnage aléatoire systématique. La prévalence de la dépression était de 47,5\%. La dépression était significativement associée à l'âge $(P=0,002)$, au niveau d'études $(P=0,015)$, au métier $(P<0,001)$, aux problèmes de vie quotidienne $(P=0,026)$, ainsi qu'aux problèmes sociaux $(P<0,001)$. Après avoir contrôlé les facteurs de confusion à l'aide de l'analyse de régression logistique multiple, nous avons constaté que la dépression était quatre fois plus fréquente chez les personnes âgées à la retraite que chez celles continuant à travailler, trois fois plus fréquente chez les personnes âgées affligées de problèmes sociaux ou atteintes d'une incontinence urinaire et deux fois plus fréquente chez les personnes âgées traversant des problèmes de vie quotidienne. 


\section{Introduction}

With no acceptable definition for "elderly", becoming eligible for statutory and occupational retirement pensions has become the default definition. The ages of 60 and 65 years are often used arbitrarily $[1,2]$. The population aged $60+$ years is estimated at nearly 1 person in 10 worldwide, with a ratio of 302 million women to 247 million men [3]. In the countries of the Arab League, the absolute number of people aged $\geq 65$ years doubled from 5.7 million in 1980 to 10.4 million in 2000 , and is expected to increase to 21.3 million by 2020 [4].

In Sudan, a developing country, little emphasis has been placed on the elderly. Khartoum, the capital, has an estimated population of approximately 5.27 million according to the 2008 population census; $20 \%$ of these are elderly [5].

Depression is a common mental disorder among the aged population; it presents with depressed mood, loss of interest or pleasure, feelings of guilt or low self-worth, disturbed sleep or appetite, low energy and poor concentration [6]. These problems can become chronic or recurrent, and can lead to substantial impairment in the ability to carry out everyday responsibilities. Depression can also lead to suicide, which accounts for the loss of about 850000 lives every year [6].

Depression is a leading cause of disability, and in 2000 it was the 4th leading contributor to the global burden of disease (measured as disability adjusted life years, or DALYs) [6]. It has been estimated that in developed countries approximately $1 \%-3 \%$ of people aged over 65 years suffer from severe depression, with a further $10 \%-15 \%$ suffering milder forms [7].

Assessment of depression in the elderly poses a challenge because it is often undiagnosed or untreated. It has been estimated that only $10 \%$ of depressed elderly persons receive treatment owing to the widespread belief that depression is normal with aging, to the denial due to shame or stigma, or to masked depression $[8,9]$.

To advocate for geriatric problems, specifically depression, among the aged population, baseline information on the burden of the disease and associated factors is required, but this is lacking in Sudan. This study is aimed at determining the prevalence of depression as a mental health problem among the elderly at community level and assessing the associated risk factors.

\section{Methods}

A community-based, analytical, crosssectional design was followed to fulfil the objectives of the study.

This study was conducted during June 2010-September 2010 in Khartoum State, which comprises 7 localities: Omdurman, Bahari, Khartoum, Ummbada, East Nile, Karari and Jabal Awliya.

\section{Assessment of aged population}

Age $60+$ years was the cut-off age we used to determine the eligible target population [1]. Any one of the following criteria was considered evidence of old age (i.e. $60+$ years): birth certificate from which age could be determined; any official document (identity card, passport, etc.) that included the age of the person; or retirement documents associated with the age at which a person begins to receive pension benefits.

For calculation of sample size, the following formula was used: $n=z^{2} \times\left(p q / d^{2}\right)$, where $n$ is the estimate of sample size; $z=1.96$, a quantile from the standard normal distribution; $p$ is the proportion of the target population with the characteristic being measured $(=0.11) ; q$ is the proportion without the characteristic $(=1-p)$; $d$ is margin of error $(=0.05)$.

Based on the above formula, estimated sample size was 150 . This was multiplied by 2 (to take into consideration design effect and effect of cluster design), to give a final sample size of 300 .

Simple random sampling was used to select 3 localities, Khartoum, Jabal Awliya, and East Nile, out of the 7 identified above. From within these 3 localities, 2 blocks were selected randomly from each locality, giving a total of 6 blocks in the 3 localities. In each block, systematic random sampling was used to select households. Based on the sample size, 50 households were randomly selected in each block. The sampling interval $(\mathrm{k})$ was determined by sample size and number of households in each block. The first household in each block was selected randomly, and then systematically each kth house anticlockwise was selected for interview. The target elderly people living in the selected households were interviewed; if no eligible person was found, the next house was selected till an eligible person found. This was continued till the desired number of participants was reached for each block. Individual oral consent was obtained from the participants after presenting a disclosure statement regarding the purpose of the research. There were no refusals to participate.

\section{Structured questionnaire}

A structured questionnaire was used to collect data from the participants. The questionnaire had 3 sections: 1) sociodemographic characteristics such as age, sex, marital status, educational attainment, employment, source of income and living conditions; 2) the screening for depression questions, (see below); and 3) self-reported health conditions, which included 14 questions pertinent to risk factors common to depression in old age experienced prior to the survey.

The data collectors were trained on the techniques for completing the questionnaire. They were successively distributed to collect primary data from households based on a detailed implementation plan.

Data were edited and analysed using SPSS, version 17. Mean and standard 
deviation, odds ratio (OR) and 95\% confidence interval (CI) were computed. Statistical significance of the results was tested using the chi-squared test, logistic and linear regression analyses and judged at the $5 \%$ level.

The analysis was done as follows: first analyses were performed separately for all the independent variables and the dependent variable (depression). Bivariate analysis was used (cross tabulation) with chi-squared statistics to test the degree of association. $P<0.05$ (2-sided) was used to determine significance. Then logistic regression analysis was used for the dependent variable with all independent variables (with significant P-value) as predictors to assess the degree of association using $\mathrm{OR}$ with $95 \% \mathrm{CI}$.

The participants were initially informed about the study, including a full explanation of the study objectives, expected outcomes, rights of respondents and confidential processing of collected data and their consent was obtained. Only oral consent was obtained from interviewees before the interview as no harm was expected because there was no intervention.

\section{Screening of depression: Geriatric Depression Scale}

Depression of aged participants at households was assessed using the short version of the standardized Geriatric Depression Scale [10], which includes 15 questions. The total possible score ranged from 0 to 15 . Higherscores reflect an increase in depressive symptoms and a score of 5 or more was set to indicate depression. The Geriatric Depression Scale (GDS) was created specifically for the use with the elderly population. It is effective amongst elderly persons residing in community settings; it is less effective with the presence of dementia. The questionnaire takes around 5-7 minutes to complete $[11,12]$. GDS-15 was already translated in Arabic. With reported prior diagnosis of depression as a criterion, the specificity of the scale is strong $(\mathrm{GDS}=0.90, \mathrm{GDSCOL}=$ 0.91 ), but the sensitivity appeared relatively low [13].

The following questions were administered and the participants were asked to answer yes or no for how they felt over the week preceding the interview.

- Are you basically satisfied with your life?

- Have you dropped many of your activities and interests?

- Do you feel that your life is empty?

- Do you often get bored?

- Are you in good spirits most of the time?

- Are you afraid that something bad is going to happen to you?

- Do you feel happy most of the time?

- Do you often feel helpless?

- Do you prefer to stay at home, rather than going out and doing new things?

- Do you feel you have more problems with memory than most?

- Do you think it is wonderful to be alive now?

- Do you feel pretty worthless the way you are now?

- Do you feel full of energy?

- Do you feel that your situation is hopeless?

- Do you think that most people are better off than you are?
- Score 1 for each "depressed" answer, i.e. "no" for questions $1,5,7,11$, and 13 , and "yes" for the others.

\section{Results}

The prevalence of geriatric depression at community level was $41.1 \%(122 / 300)$. Most of the respondents $56.7 \%$ were in the age group 60-69 years (Table 1). The proportion of males was $53 \%$.

The prevalence of depression among age group 60-69 years was 33.9\% ( $P=$ 0.002 ) and prevalence increased with increasing age (chi squared $=12.325, \mathrm{df}$ $=2)$. The difference was significant $(P<$ 0.05) (Table 2).

There was evidence against of an association between depression and age $(P=0.002)$, level of education $(P$ $=0.015)$, occupation $(P<0.001)$, the problems of everyday living (such as food, clothing, housing, transportation, furniture, medical treatment costs, children's education) $(P=0.026)$, social problems (such as inability to visit friends and relatives, being worried about the children's future, feeling lonely, having no friends $)(P<0.001)$ (Table 3).

We found that a number of common geriatric medical problems were associated with depression, namely memory loss $(P<0.001)$, urinary incontinence $(P=0.001)$, rheumatoid arthritis $(P=0.005)$, Parkinsonism $(P$

\begin{tabular}{lcc}
\hline $\begin{array}{l}\text { Table } 1 \text { Distribution of the study population }(\boldsymbol{n}=\mathbf{3 0 0}) \text { by age and sex, Khartoum } \\
\text { State, } 2010\end{array}$ & No. \\
\hline Characteristic & 169 & 56.7 \\
Age (years) & 100 & 33.6 \\
$\quad 60-69$ & 29 & 9.7 \\
$70-79$ & 298 & 100.0 \\
$80+$ & & \\
Total & 159 & 53.0 \\
Sex & 141 & 47.0 \\
Male & 300 & 100.0 \\
Female & & \\
Total &
\end{tabular}


Table 2 Prevalence of depression among the elderly $(n=300)$, by age group, Khartoum State, 2010

\begin{tabular}{lccccccc}
\hline Age (years) & \multicolumn{2}{c}{ Depressed } & \multicolumn{2}{c}{ Not depressed } & \multicolumn{2}{c}{ Total } \\
& No. & $\%$ & No. & $\%$ & No. & $\%$ & 100 \\
$60-69(n=168)$ & 57 & 33.9 & 111 & 66.1 & 168 & 99 & 100 \\
$70-79(n=99)$ & 44 & 44.4 & 55 & 55.6 & 32.1 & 33 & 100 \\
$80+(n=28)$ & 22 & 67.9 & 11 & 33 & \\
\hline
\end{tabular}

$=0.007)$ and Alzheimer's disease $(P=$ showed that depression was significantly 0.048) (Table 4).

After controlling for confounders, problems (adjusted $\mathrm{OR}=3.2 ; 95 \% \mathrm{Cl}$ the overall model of logistic regression $1.45-7.41 ; P=0.0004)$, problems of $95 \% \mathrm{CI}: 1.27-1.76 ; P=0.017)$ (Table 5).

\begin{tabular}{|c|c|c|c|c|c|c|}
\hline \multirow[t]{2}{*}{ Variable } & \multicolumn{2}{|c|}{ Not depressed } & \multicolumn{2}{|c|}{ Depressed } & \multirow[t]{2}{*}{$x^{2}$} & \multirow[t]{2}{*}{$P$-value } \\
\hline & No. & $\%$ & No. & $\%$ & & \\
\hline Age (years) & & & & & 12.325 & 0.002 \\
\hline $60-69(n=168)$ & 111 & 66.1 & 57 & 33.9 & & \\
\hline $70-79(n=99)$ & 55 & 55.6 & 44 & 44.4 & & \\
\hline $80+(n=28)$ & 9 & 32.1 & 19 & 67.9 & & \\
\hline Sex & & & & & 2.662 & 0.103 \\
\hline Male $(n=158)$ & 100 & 63.3 & 58 & 36.7 & & \\
\hline Female $(n=139)$ & 75 & 54.0 & 64 & 46.0 & & \\
\hline Level of education & & & & & 15.814 & 0.015 \\
\hline Illiterate $(n=143)$ & 70 & 49.0 & 73 & 51.0 & & \\
\hline Read \& write $(n=49)$ & 33 & 67.3 & 16 & 32.7 & & \\
\hline Primary $(n=35)$ & 20 & 57.1 & 15 & 42.9 & & \\
\hline Intermediate $(n=25)$ & 21 & 84.0 & 4 & 16.0 & & \\
\hline Secondary $(n=21)$ & 14 & 66.7 & 7 & 33.3 & & \\
\hline University $(n=20)$ & 14 & 70.0 & 6 & 30.0 & & \\
\hline Postgraduate $(n=4)$ & 3 & 75.0 & 1 & 25.0 & & \\
\hline Marital status & & & & & 1.901 & 0.539 \\
\hline Married $(n=154)$ & 95 & 61.7 & 59 & 38.3 & & \\
\hline Divorced $(n=1)$ & 1 & 100.0 & 0 & 0.0 & & \\
\hline Widowed $(n=136)$ & 76 & 55.9 & 60 & 44.1 & & \\
\hline Unmarried $(n=6)$ & 3 & 50.0 & 3 & 50.0 & & \\
\hline Occupation & & & & & 15.426 & $<0.001$ \\
\hline Working $(n=41)^{\mathrm{a}}$ & 35 & 85.4 & 6 & 14.6 & & \\
\hline Retired $(n=106)$ & 63 & 59.4 & 43 & 40.6 & & \\
\hline Not working $(n=150)$ & 77 & 51.3 & 73 & 48.7 & & \\
\hline Problems of everyday living & & & & & 5.422 & 0.026 \\
\hline Yes $(n=106)$ & 53 & 50.0 & 53 & 50.0 & & \\
\hline No $(n=191)$ & 122 & 63.9 & 69 & 36.1 & & \\
\hline Social problems ${ }^{c}$ & & & & & 30.769 & $<0.001$ \\
\hline Yes $(n=59)$ & 16 & 27.0 & 43 & 73.0 & & \\
\hline No $(n=238)$ & 159 & 67.0 & 79 & 33.0 & & \\
\hline
\end{tabular}

${ }^{a}$ Some people had retired from government work, according to the rules, but found a job in the private sector. ${ }^{b}$ Having less than 2 meals per day as a proxy indicator of problems of everyday living and only one set of clothes. If both are present, this was considered a living problem.

cLiving alone; detached from children and relatives. 


\begin{tabular}{|c|c|c|c|c|c|c|c|}
\hline \multirow[t]{2}{*}{ Risk factor } & \multicolumn{2}{|c|}{ Not depressed } & \multicolumn{2}{|c|}{ Depressed } & \multirow{2}{*}{$\begin{array}{c}\text { Total } \\
\text { No. }\end{array}$} & \multirow[t]{2}{*}{$x_{1}^{2}$} & \multirow[t]{2}{*}{$P$-value } \\
\hline & No. & $\%$ & No. & $\%$ & & & \\
\hline \multicolumn{8}{|c|}{ Memory loss } \\
\hline No & 156 & 64.7 & 85 & 35.3 & 241 & \multirow{2}{*}{17.812} & \multirow{2}{*}{$<0.001$} \\
\hline Yes & 19 & 33.9 & 37 & 66.1 & 56 & & \\
\hline \multicolumn{8}{|l|}{ Sadness } \\
\hline No & 150 & 66.1 & 77 & 33.9 & 227 & \multirow{2}{*}{20.381} & \multirow{2}{*}{$<0.001$} \\
\hline Yes & 25 & 35.7 & 45 & 64.3 & 70 & & \\
\hline \multicolumn{8}{|c|}{ Parkinson disease } \\
\hline No & 174 & 60.2 & 115 & 39.8 & 289 & \multirow{2}{*}{7.320} & \multirow{2}{*}{0.007} \\
\hline Yes & 1 & 12.5 & 7 & 87.5 & 8 & & \\
\hline \multicolumn{8}{|c|}{ Alzheimer disease } \\
\hline No & 173 & 59.9 & 116 & 40.1 & 289 & \multirow{2}{*}{3.909} & \multirow{2}{*}{0.048} \\
\hline Yes & 2 & 25.0 & 6 & 75.0 & 8 & & \\
\hline \multicolumn{8}{|c|}{ Rheumatoid arthritis } \\
\hline No & 116 & 65.5 & 61 & 34.5 & 177 & \multirow{2}{*}{7.918} & \multirow{2}{*}{0.005} \\
\hline Yes & 59 & 49.2 & 61 & 50.8 & 120 & & \\
\hline \multicolumn{8}{|c|}{ Urinary incontinence } \\
\hline No & 167 & 62.1 & 102 & 37.9 & 269 & \multirow{2}{*}{11.766} & \multirow{2}{*}{0.001} \\
\hline Yes & 8 & 28.6 & 20 & 71.4 & 28 & & \\
\hline
\end{tabular}

\section{Discussion}

The proportion of males in our study sample was $53 \%$ and females $47 \%$, a finding which is line with the elderly population demographic in Sudan, where the proportion of males aged $60+$ years is $56 \%$, and females $44 \%$ [5]. The overall prevalence of geriatric depression at community level was $41.1 \%$, which is higher than the total rate of depression found among older adults in a study in Egypt, 30\% [11].

A similar prevalence for depression was reported from a study in a rural area of Russia which was experiencing demographic and epidemiological changes [14].
Among the study population, depression was found to be associated with age, especially the age group 60-69 years. At this age, the transitional period starts changing the lives of the elderly; they retire and suffer from a reduction in their social activities and their roles. This change exerts a considerable burden of stress on the

\begin{tabular}{lccc}
\hline Table 5 Logistic regression analysis of risk factors associated with depression in the elderly, Khartoum State, 2010 \\
\hline Factor & Adjusted OR & $\mathbf{9 5 \%}$ Cl & $0.017^{*}$ \\
Occupation (retired) & 3.876 & $1.27-11.76$ & $0.004^{*}$ \\
Social problems & 3.27 & $1.45-7.41$ & 0.079 \\
Urine incontinence & 2.73 & $0.89-8.36$ & 0.441 \\
Level of education & 2.723 & $0.21-34.72$ & $0.011^{*}$ \\
Problems of everyday living & 2.19 & $1.19-3.94$ & 0.550 \\
Parkinson disease & 2.104 & $0.18-24.06$ & 0.159 \\
Memory loss & 1.758 & $0.80-3.86$ & 0.392 \\
Age & 1.652 & $0.19-1.91$ & 0.400 \\
Rheumatoid arthritis & 1.287 & $0.72-2.32$ & 0.598 \\
Support from family & 1.236 & $0.56-2.71$ & 0.918 \\
Alzheimer disease & 1.108 & $0.13-6.43$ & 0.817 \\
Social problems & 1.097 & $0.42-2.00$ & \\
\hline
\end{tabular}

*Statistically significant at $P<0.05$.

$O R=$ odds ratio $; C l=$ confidence interval . 
elderly leading to anxiety and depression [11].

Depression was not significantly associated with sex. This finding is contradictory to the results of other studies where depression was found to be more common among females: it has been reported that the lifetime prevalence of depression was $9.1 \%$ in women and $2.9 \%$ in men [15]. This difference could be related to the nature of the extended family in Sudanese society, where the role of older ladies as grandmothers is respected by other family members [A. Suliman. Assessment of health status of elders at two old homes in Khartoum Sudan, 2000. Unpublished study]

The prevalence of depression among elderly women $46 \%$ was higher than in other countries in the Eastern Mediterranean Region, for example, depression among elderly females reached $27.7 \%$ in Saudi Arabia [16] and 29.6\% in Lebanon (outskirts of Beirut [17].

We found that those with lower education levels were more likely to be depressed, contrasting with the findings of a study in Sweden (a country with contrasting education levels, economy, income levels, culture and religion), where education was unrelated to depression in men and women overall. However, a strong association between occupation and depression was found in both studies: those who were retired were more likely to be depressed than those who were working [18]. Also, problems of everyday living and social problems were associated with increased risk of depression, which is similar to the findings of the Swedish study [18].
There was no association between marital status and depression; this differed from the findings of a similar study in Quebec (Canada), another country where lifestyles differ greatly from lifestyles in Sudan, in which it was reported that men without a partner tended to consult for depression more frequently than men with a cohabiting partner [19].

Although all medical problems were individually significantly associated with depression, in logistic regression modelling they were not identified as risk factors. Similar results were found in a study in Australia, indicating that socioeconomic factors were more important than medical problems [20].

Funding: This research was funded by Khartoum State Ministry of Health.

Competing interests: None declared.

\section{References}

1. Roebuck J. When does old age begin?: the evolution of the English definition. Journal of Social History, 1979, 12(3):416-428.

2. Thane P. The muddled history of retiring at 60 and 65 . New Society, 1978, 45(826):234-236.

3. Index Mundi. World demographics profile, 2013. (website) (http://www.indexmundi.com/world/demographics_profile.html, accessed 24 March 2013).

4. Population aging in Arab countries. Beirut, United Nations Economic and Social Commission for Western Asia (ESCWA), 2007 (E/ESCWA/SDD/2007/Technical Material).

5. [Sudan population census statistical report]. Khartoum, Federal Ministry of Health, 2010 [in Arabic].

6. Debjit bhowmik KP et al. Depression - symptoms, causes, medications and therapies. Pharma Innovation, 2012, 1(3):3751.

7. National advisory council on aging. Dealing with depression. Newsletter, 2000, 13(3).

8. The state of mental health and aging in America, Issue Brief 1: What do the data tell us? Atlanta, Georgia, Centers for Disease Control and Prevention \& National Association of Chronic Disease Directors, 2008.

9. Costa PT, Metter EJ, McCrae RR. Personality stability and its contribution to successful aging. Journal of Geriatric Psychiatry, 1994, 27:41-59.

10. Yesavage JA et al. Development and validation of a geriatric depression screening scale: a preliminary report. Journal of Psychiatric Research, 1982-1983, 17:37-49.

11. Mahfouz EM, Mahfouz MM. Comparing three clinical screening tools in identification of geriatric depression in a rural community setting. Egyptian Journal of Community Medicine, 2008, 26(3).
12. Greenberg SA. The Geriatric Depression Scale (GDS). New York, Hartford Institute for Geriatric Nursing, NYU College of Nursing 2012 (General assessment series, Issue Number 4, Revised).

13. Wrobel NH, Farrag MF. A preliminary report on the validation of the Geriatric Depression Scale in Arabic. Clinical Gerontologist, 2006, 29(4):33-46.

14. Pakriev S, Shlik J, Vasar V. Course of depression: findings from cross-sectional survey in rural Udmurtia. Nordic Journal of Psychiatry, 2001, 55:185-189.

15. Moreno MP et al. Mental health in senior citizens in the metropolitan zone of Guadalajara. Aging Clinical and Experimental Research, 1999, 11:96-100.

16. Al-Shammari SA, Al-Subaie A. Prevalence and correlates of depression among Saudi elderly. International Journal of Geriatric Psychiatry, 1999, 14:739-747.

17. 18.Bassem RS et al. Determinants of depression among poor elderly women: findings from refugee and non-refugee communities in the outskirts of Beirut, Lebanon. European Journal of Psychology, 2005, 1(3):

18. Kosidou K et al. Socioeconomic status and risk of psychological distress and depression in the Stockholm Public Health Cohort: a population-based study. Journal of Affective Disorders, 2011, 134:160-167.

19. Mechakra-Tahiri SD et al. Associations of social relationships with consultation for symptoms of depression: a community study of depression in older men and women in Québec. Psychological Reports, 2011, 108:537-552.

20. Sims J et al. Urinary incontinence in a community sample of older adults: prevalence and impact on quality of life. Disability and Rehabilitation, 2011, 33:1389-1398. 